\title{
Unflushable or missing toilet paper, the dilemma for developing communities during the COVID-19 episode
}

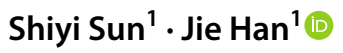

Received: 15 July 2020 / Accepted: 28 July 2020 / Published online: 8 August 2020

(c) Springer Nature Switzerland AG 2020

\begin{abstract}
Unlike in developed countries, most public toilets in China do not provide toilet paper onsite and users must bring their toilet paper. Moreover, an open waste bin is placed in each user's cubicle to collect used toilet paper and tissues. Such practices, which are common in East Asia and central America, have induced a dilemma of toilet paper disposal because some municipalities have removed waste bins from public toilets to prevent virus transmission by fecal matter. As a consequence, users were forced to flush down their used toilet paper and tissues. Yet, it is unknown whether standard toilet paper can be flushed easily without causing issues in sewer operations. Here, we surveyed the conditions of toilets in university campus and other public facilities in different regions across China. We also evaluated the disintegration characteristics of toilet paper products both by conducting online surveys and by physical disintegration experiments. We found that only $15 \%$ of toilets provided toilet paper, while open waste bins occurred at nearly all sites. Further, our survey indicated that $82 \%$ of toilet paper products sold in China did not give any indication on their flushability, whereas $77 \%$ of US products did. Disintegration results showed that none of the five popular, best-selling toilet paper products passed the flushability standard. We propose strategies to solve the current toilet paper dilemma in developing communities.
\end{abstract}

Keywords Coronavirus $\cdot$ Public toilet $\cdot$ Restroom $\cdot$ Flushability $\cdot$ Disintegration $\cdot$ Sewer

\section{Introduction}

The ongoing COVID-19 pandemic is presenting a major challenge on the inadequate waste management practices in developing regions. Recent discussions highlighted the risks of fecal and sewage-associated exposure to the novel coronavirus, SARS-CoV-2, in vulnerable communities (Daughton 2020; Heller et al. 2020; Usman et al. 2020). Restrooms are not only a major source of the SARS-CoV-2 virus entering municipal sewage, but a high-risk environment for direct transmission of the virus via human excreta. Public toilets with high foot traffic such as those located in airports, train stations, schools, hospitals, and office buildings are potential hot spots. On June 29, the government of Beijing confirmed that two individuals were infected with the SARS-CoV-2 virus after using a public toilet, which

Jie Han

jiehan@xjtu.edu.cn

1 Department of Environmental Science and Engineering, Xi'an Jiaotong University, Xi' an 710049,

People's Republic of China became the first case of SARS-CoV-2 transmission in public toilet environments in the country (PGBM 2020). The public briefing highlighted inadequate ventilation and poor sanitary conditions in some public toilets as potential contributors to virus transmission.

There are about 196,000 public toilets in cities and prefectures across mainland China (MOHURD 2019). Unlike those in developed countries (FDA 2017), the vast majority of public toilets in China, including those in schools and workplaces, do not provide toilet paper on site (MOHURD 2017). People are accustomed to bringing their own toilet paper, tissues, or other usable alternatives at hand, when using these facilities (Yao et al. 2018). To avoid incompatible materials being flushed into sewers, most public toilets provide an open waste bin in each user's cubicle for collecting used toilet papers and materials. While it may appear astonishing to some foreign visitors, such practice is in fact quite common in developing regions in East Asia (ASEAN 2012) and central America (WeExpats 2018). A recent survey in China found that over $80 \%$ of the survey respondents $(n=200)$ would voluntarily put their used toilet tissues into the waste bins in place (Yao et al. 2018). 
In these communities, the COVID-19 pandemic has created an unexpected dilemma in their disposal of used toilet paper (Fig. 1). SARS-CoV-2 has been detected in viable forms and high viral loads in human feces (Park et al. 2020; Wu et al. 2020) and may survive for prolonged periods on solid materials including paper products (van Doremalen et al. 2020; Sharma et al. 2020). In light of the risk of virus transmission via fecal matter, some municipalities in China mandated the removal of waste bins from public toilets and instead suggested users to flush down their used toilet paper and tissues (Hebei 2020; Zhejiang 2020). Such a precautionary measure, however, could bring issues to their local plumbing and sewer operations. The toilet paper varieties sold in the domestic market in China are known to have widespread quality issues. An inspection in 2019 covering toilet paper products from 38 manufacturers in nine provinces and municipalities found that $37.5 \%$ of those products did not conform to the national quality standard (Shao et al. 2020). More importantly, their disintegration characteristics in water-the key factor determining the "flushability" of toilet paper-are not regulated by the current standard (GB Standards 2018). Once flushed into sewers, toilet paper with poor disintegration characteristics, along with other types of incompatible materials (e.g., facial tissues, wipes), may cause pipe blockage or pump failure which could further lead to sanitary sewer overflows (Durukan and Karadagli 2019; Eren and Karadagli 2012), posing a significant threat to public health with risks of community outbreaks of diseases, chemical leakages, and industrial waste spills (Daghrir and Drogui 2013; EPA 2004; Heim and Schwarzbauer 2013; Regnery et al. 2019; Tijani et al. 2016).

In this work, we highlight these issues by surveying the conditions of public toilets at various facilities, including locations with high user traffic such as schools, government public service departments, workplaces, apartment complexes, and off-street convenience restrooms. Further, we surveyed over 90 best-selling toilet paper products in China and the USA with emphases on their ability to disintegrate or "dissolve" in water. To validate our findings, we evaluated the physical disintegration characteristics of several bestselling toilet papers in the country by following the experimental protocols of the flushability standard. Specifically, we want to address the following key hypotheses through this study: (1) Do most public toilets in China provide toilet paper or open waste bins and are such practices common in other developing nations? (2) Are most toilet paper products
Fig. 1 Unflushable toilet paper presents a dilemma for developing communities during the COVID-19 pandemic. a A user followed the standard practice by disposing used toilet paper in an open waste bin onsite. During COVID-19, some municipalities mandated the removal of waste bins from public toilets, leaving users to wonder whether they should flush their toilet paper down the drain. $\mathbf{b} \mathrm{A}$ typical cubicle in a public toilet in mainland China. $\mathbf{c}$ Used toilet paper and tissues disposed of by users in an open waste bin, presenting a potential source of fecal transmission. d Non-flushable toilet paper showed no sign of disintegration after two hours of agitation in water (100 rpm)

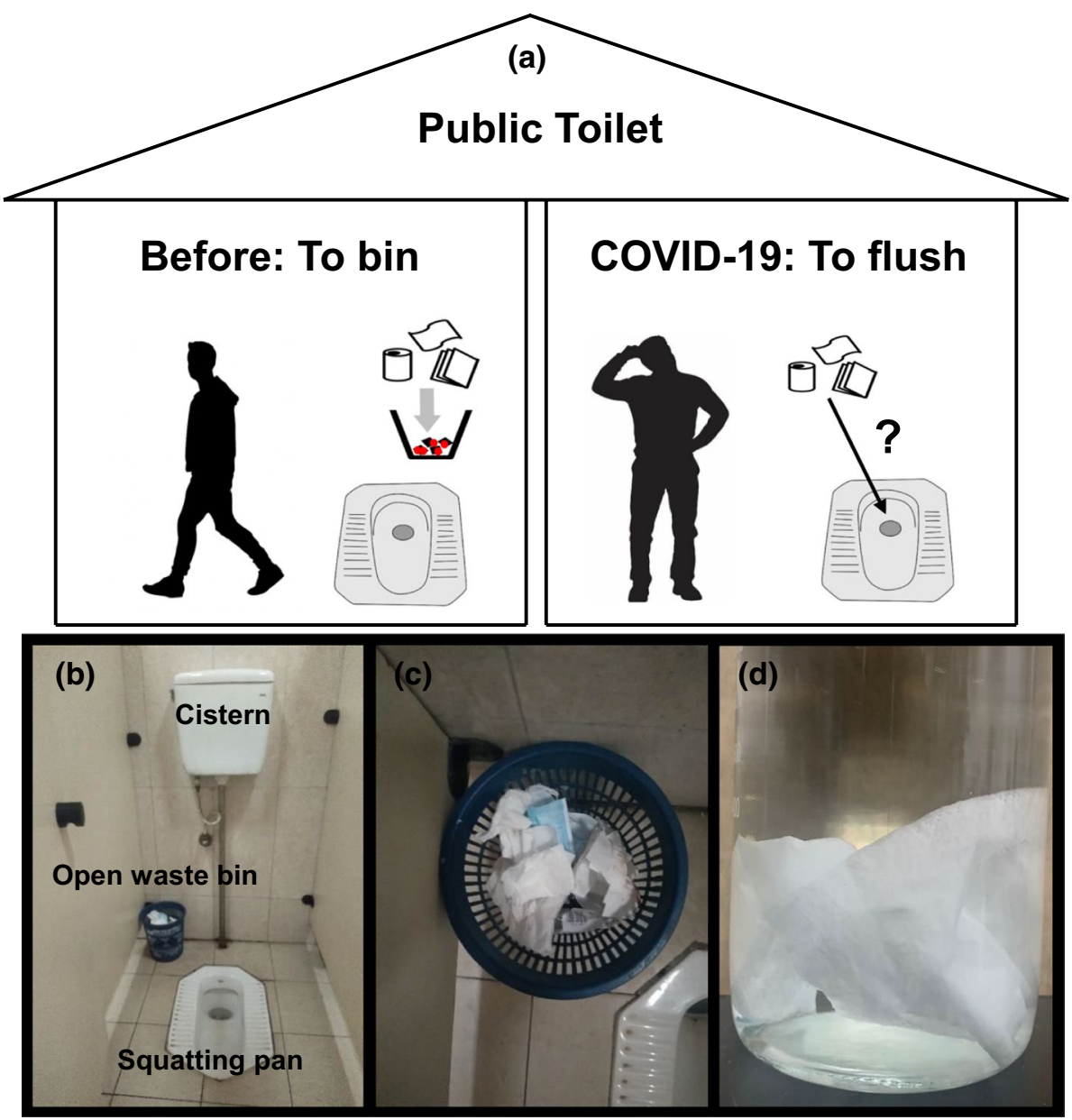


sold in the domestic market deemed flushable, and if not are they different from those sold in developed countries in terms of flushability? (3) Are there any quality standards in place to regulate the physical disintegration characteristics of toilet paper products sold in China? By reviewing the mitigation efforts recently put by some local municipalities, we offer some strategies for developing communities facing the current dilemma and further find a long-term solution by referencing the current practices in developed nations to bridge this neglected gap in public health management.

\section{Experimental}

\section{Field and online surveys}

We surveyed the conditions of public toilets $(n=65)$ at locations with high user traffic including libraries, dining commons, auditoriums, and classroom buildings at Xi' an Jiaotong University on July 8-10, 2020. We also called for volunteers in six provinces to submit photographs of their nearby toilets open for public use $(n=8)$ at various types of facilities including government public service departments, retail banks, information technology companies, common areas in apartment complexes, as well as off-street "convenience toilets" in neighborhoods. We surveyed the best-selling products $(n=91)$ in the toilet paper product category based on published sales statistics from the largest online retailers in the USA and China including Walmart.com, Amazon. com, Taobao/Tmall.com, and JD.com, to gather information on these products with respect to their suitability to be flushed down the drain.

\section{Physical disintegration experiments}

We purchased four top-selling toilet paper rolls ranked \#1-8 on JD.com and Taobao/Tmall.com. Two additional products, including a compact-size pack of facial tissues and a toilet paper roll with a "flushable" label, were selected as controls. Products were selected in a random manner and solely based on their popularity among domestic consumers according to sales statistics shown by the three largest online retailers in the country, with the only exception of the flushable control which was an unpopular entity in this product category. The small pack of facial tissues was included for both its high popularity and ultra-compact size which makes it easy to carry and a convenient substitute to use in public toilets with no provision of toilet paper onsite.

Physical disintegration experiments were conducted on the selected products by following the standard protocols for assessing the flushability of paper products (Eren and Karadagli 2017; TAPPI 2017). First, we added 1000 mL tap water into glass beakers that were fixated on an IKA ${ }^{\circledR}$
KS-260 platform shaker. Samples with an area size of $c a$. $200 \mathrm{~cm}^{2}$ were cut from their original rolls or packs and weighed on a two-decimal balance (Mettler ME2002) before being fully immersed in the beakers with circular flat bottoms. Samples were continuously agitated at 100 rotations per minute. After two hours, we removed beakers from the shaker and performed a visual inspection on the sample material in each beaker. Samples showing no sign of physical intergradation after the experiment were recorded and not treated further. For those showing partial or complete integration, contents in the beaker were passed through a stainless-steel sieve with 6.0-mm holes. Solid material residues left on the sieve were then collected and dried overnight in an incubator oven at $60{ }^{\circ} \mathrm{C}$ to determine their dry weight and compared with the acceptance criteria by the flushability standard.

\section{Results and discussion}

\section{Surveys on public toilets and toilet paper products}

Given the large number of photographs taken through our surveys, examples showing the typical conditions of the toilets we surveyed are shown in Fig. 2. Out of the 73 locations we surveyed, only few of them $(n=11)$ provided toilet paper onsite. Our surveys identified several common practices in public toilets, regardless of the geographical regions or the types of facilities they were located at. Specifically, a similar design was found with respect to the provision of open waste bins for the disposal of used toilet paper by users. These were found to be ubiquitously common in toilets in all locations we surveyed, from schools to workplaces across the country.

Our survey on top-selling toilet paper from the three largest domestic online retailers showed that most of the products $(82 \%, n=55)$ did not give any indication on their suitability to be flushed down the drain, nor was there any testing result provided on their physical disintegration in water (Tmall, JD, Suning.com 2020). On the contrary, a majority of those products claimed their strength and durability after wetting by providing either graphical evidence or testing results from manufacturers. It is worthwhile to note that their ability in retaining strength in wet states would be user-friendly, but it is also a culprit causing blockage and other problems in sewer operations (Durukan and Karadagli 2019).

The toilet paper products sold in the US market offer a highly contrasting example. The Technical Association of the Pulp and Paper Industry in the USA provides explicit definitions for "flushable" products that will quickly break into small pieces in water and not be buoyant (TAPPI 2017). Our online survey of the toilet paper sold by Walmart and 
Fig. 2 Photographs of toilets for public access at various facilities in different geographical regions across mainland China. a A toilet open to employees and visitors at a government public service department in Gansu, b an off-street convenience toilet in a neighborhood in Hebei, $\mathbf{c}$ a public toilet in an apartment complex in Fujian, d one of the 65 toilets surveyed on campus at XJTU in Shaanxi, e a toilet open to customers at a retail bank in Zhejiang, $\mathbf{f}$ a toilet open to employees at an information technology company in Sichuan

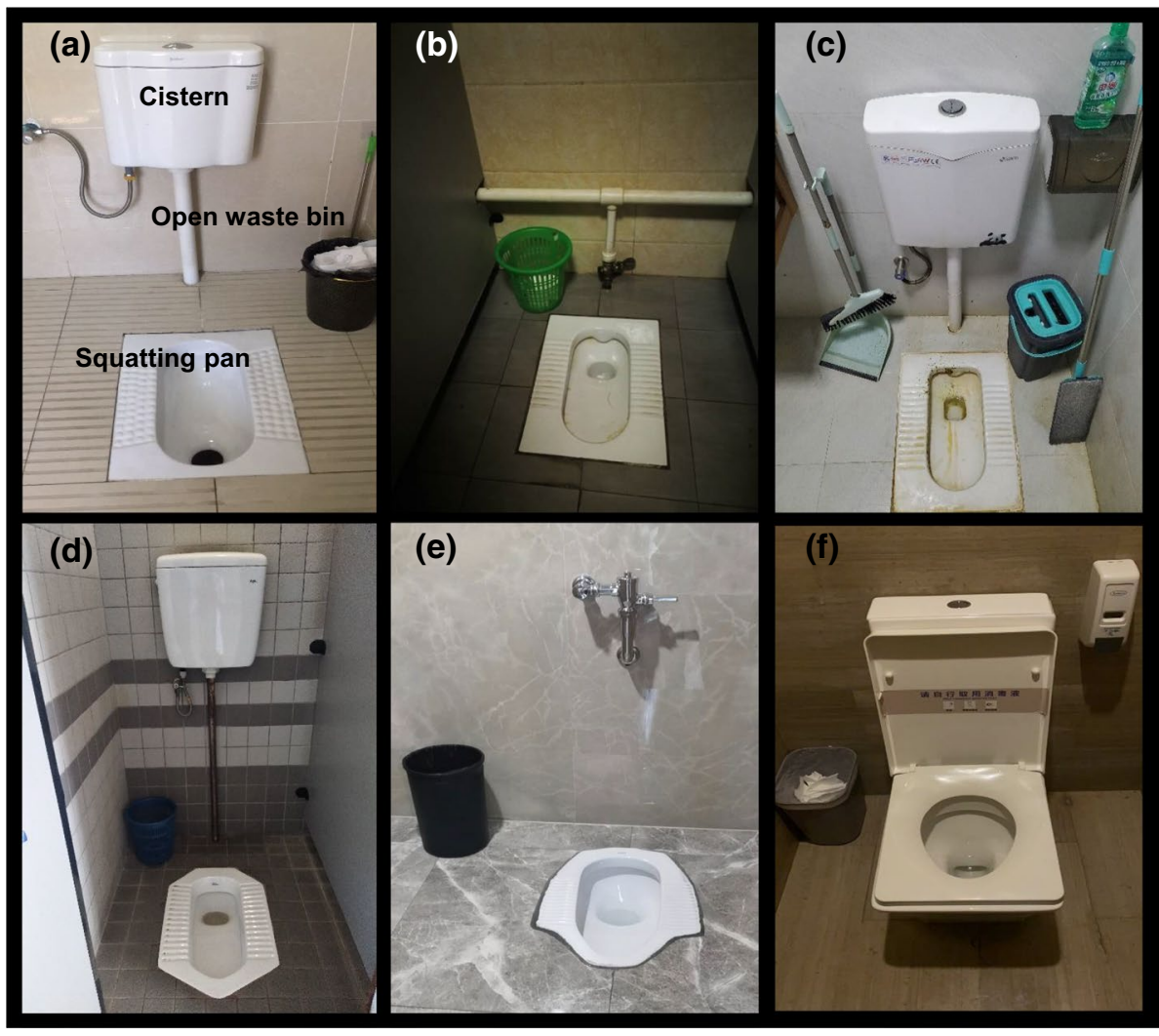

Amazon.com showed that a majority of those products (77\%,n=36) had a "septic-tank safe" or "flushable" label to inform consumers on their ability to quickly disintegrate in water (Walmart and Amazon 2020). Adding to this disparity, the sewer pervasion rates, per capita lengths, and efficiency of sewage treatment are significantly lower in developing communities than those typically found in developed countries, while sub-standard designs are common in some municipalities (Chatterjee et al. 2016; Dsikowitzky et al. 2017; Huang et al. 2018; Madhura et al. 2019). Overall, our finding showed that only $15 \%$ of the public toilets we surveyed provided toilet paper in place, and most toilet paper products sold in the domestic market provide no information with respect to their disintegration characteristics.

\section{Physical disintegration tests}

Our laboratory tests on several best-selling toilet paper products further validated findings in our product survey (Fig. 3). Predictably, none of those products broke or dissolved in water after two hours of agitation in water at $100 \mathrm{rpm}$. Only one product (\#1) - apart from the flushable control (\#6) — showed some degree of disintegration, although it left an excessive quantity of solid residues (93.8\%, dry weight) on the $6.0-\mathrm{mm}$ sieve which failed to meet the flushable standards $(<5 \%)$. The flushable control (\#6) which had a label on its packaging indicating its ability to quickly disintegrate in water, on the other hand, exceeded this criterion by having only $2.5 \%$ of solid residues on the sieve after the experiment. It is noteworthy that this particular product ranked very low by sales based on latest statistics from all major domestic online retailers and thus had a very small user base in the country. All other products (\#2 to \#5) exhibited little change after the experiment, showing well-preserved shapes and textures in their wetted state (Fig. 3). From these results, it can be hypothesized that should COVID-19 trigger a widespread change in people's behavior in their disposal of toilet paper, in public facilities and at home, large quantities of unsuitable materials with poor disintegration characteristics would be flushed into public sewer systems. Although there are no official statistics on the occurrence of sanitary sewer overflows in China, recent reports in Australia (Jacques 2020), the UK (BBC 2020), and the USA (Parker 2020; Williams 2020) showed dramatical increases of sewer-related incidents due to periodic shortages of toilet paper in some communities through the pandemic, which resulted in the flushing of incompatible materials including paper towels and baby wipes into the sewers. Our results suggest that similar risks exist in those developing communities where unflushable toilet paper and tissues are flushed into toilets due to their change of policy and users' behavior during the current pandemic. 

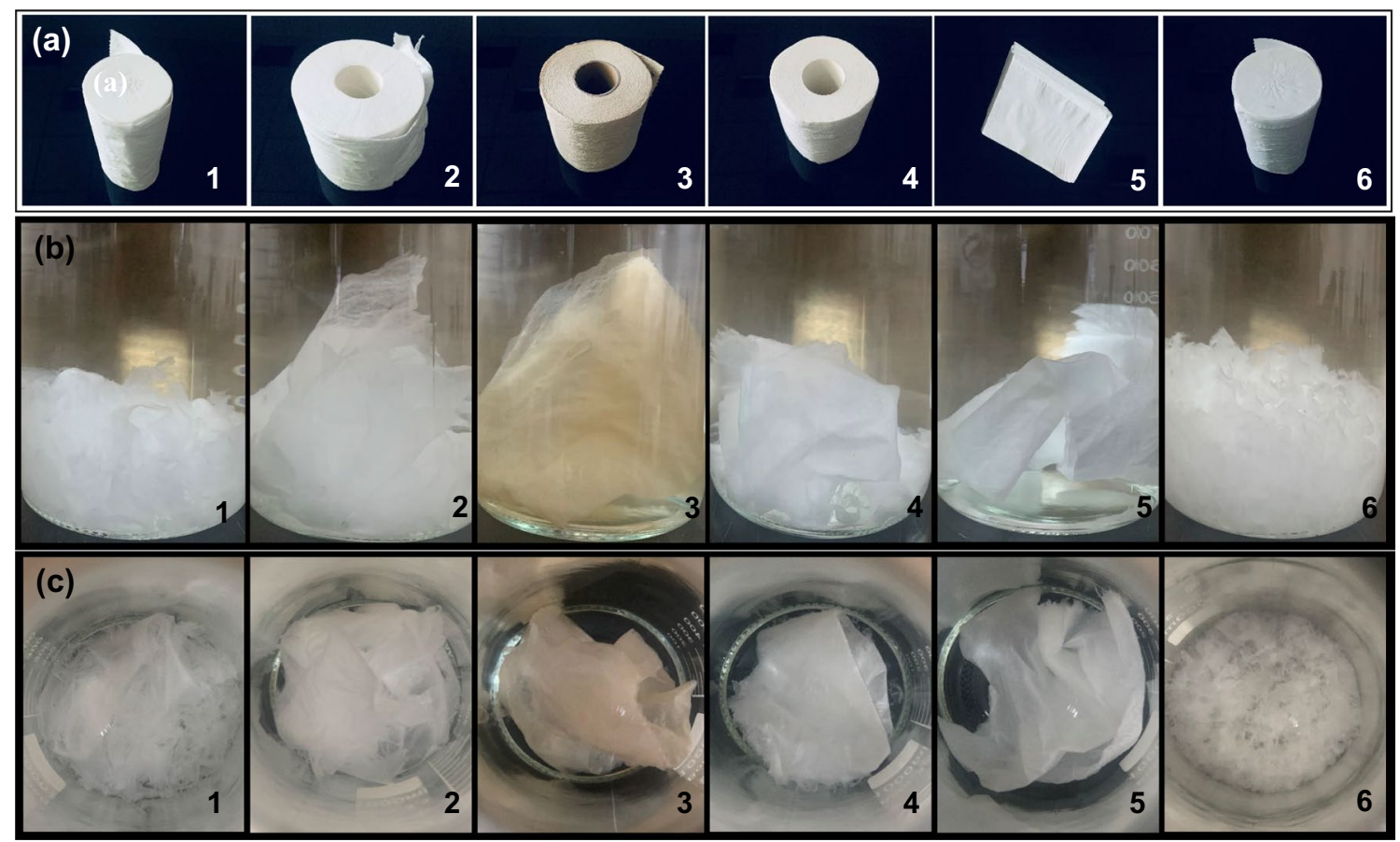

Fig. 3 Physical disintegration of four best-selling toilet paper rolls (\#1-\#4) and two controls including a popular compact-size facial tissue pack (\#5) and a flushable toilet roll (\#6). a Original products in

\section{Strategies for developing communities}

After the lockdown periods, people in regions recovering from the pandemic have begun to resume to their normal lives by returning to workplaces and schools, where the use of public toilets becomes inevitable. With the virus still looming in our communities, some municipalities in China have attempted to solve the current dilemma with a technological fix. Along with their removal of waste bins, rapiddissolving toilet paper was provided to users free of charge at some public toilets (Chongqing 2020). This perhaps sets a useful example for other developing communities facing a similar dilemma during the current pandemic. Given that open-top squatting pans are pervasively common in developing countries (ASEAN 2012), we recommend that toilet paper should be placed in dispensers with a close-lid design at these facilities to avoid contamination by splashes and droplets generated from open flushing. In the long term, we suggest the inclusion of an Acceptable Quality Limit on the physical disintegration of toilet paper in current standards by referencing the ISO/DIS 12625-17 standard, while encouraging voluntary actions from manufacturers to meet such criteria during the transition period. In the meantime, scientists and regulators should promote public awareness on the proper use and disposal of toilet paper to reduce incidents in sewer operation and potential transmission of pathogens via human wastes in developing communities (EPA 2020). dry state, $\mathbf{b}$ side views and $\mathbf{c}$ top views of sample products after standard flushability tests

\section{Conclusion}

Squatting pans, open waste bins, and no provision of toilet paper are common practices in public toilets across mainland China. Due to COVID-19, some municipalities mandated the removal of waste bins from public toilets and suggested users to flush down their used toilet paper and tissues to prevent virus transmission via human excreta. This change of habit presents a dilemma to these communities given the fact that many toilet paper products sold in the country have severely inadequate physical disintegration characteristics. None of the five best-selling products tested in this study was deemed flushable by current standards. Flushing these incompatible materials into public sewers could cause blockage and pump failure. There is an urgent need to remove waste bins from toilets open to public use while providing flushable toilet paper to users onsite. Referencing current practices in developed countries, adding an Acceptable Quality Limit on the physical disintegration of toilet paper would be the preferred longterm solution to address this public health concern.

Acknowledgements This work was funded by the Young Talent Support Plan of Xi' an Jiaotong University. Authors also thank volunteers in different geographical regions for their timely contribution in submitting photographs of toilets for public access at various facilities. 


\section{Compliance with ethical standards}

Conflict of interest Authors declare no conflict of interest in this work.

\section{References}

ASEAN (2012) Association of Southeast Asian Nations. ASEAN public toilet standard. https://www.asean.org/wp-content/uploa ds/2012/05/ASEAN-Public-Toilet-Standard.pdf. Accessed 15 Jul 2020

BBC (2020) Coronavirus: toilet roll alternatives blocking sewers. https://www.bbc.com/news/uk-england-tyne-51980820. Accessed 12 July 2020

Chatterjee P, Changrekar MM, Rao S (2016) Low efficiency of sewage treatment plants due to unskilled operations in India. Environ Chem Lett 14(3):407-416. https://doi.org/10.1007/s1031 1-016-0551-9

Chongqing Municipality (2020) Guidance for public toilet management. https://cgj.cq.gov.cn/zwgk_173/fdzdgknr/lzyj/qtgw/20200 3/t20200326_6219052.html. Accessed 15 Jul 2020

Daghrir R, Drogui P (2013) Tetracycline antibiotics in the environment: a review. Environ Chem Lett 11(3):209-227. https://doi. org/10.1007/s10311-013-0404-8

Daughton CG (2020) Wastewater surveillance for population-wide Covid-19: the present and future. Sci Total Environ 736:139631. https://doi.org/10.1016/j.scitotenv.2020.139631

van Doremalen N, Bushmaker T, Morris DH et al (2020) Aerosol and surface stability of SARS-CoV-2 as compared with SARS-CoV-1. N Engl J Med 382(16):1564-1567. https://doi. org/10.1056/NEJMc2004973

Durukan S, Karadagli F (2019) Physical characteristics, fiber compositions, and tensile properties of nonwoven wipes and toilet papers in relevance to what is flushable. Sci Total Environ 697:134135. https://doi.org/10.1016/j.scitotenv.2019.134135

Dsikowitzky L, Schaefer L et al (2017) Evidence of massive river pollution in the tropical megacity Jakarta as indicated by faecal steroid occurrence and the seasonal flushing out into the coastal ecosystem. Environ Chem Lett 15(4):703-708. https:// doi.org/10.1007/s10311-017-0641-3

EPA (2004) U.S. environmental protection agency. Report to congress: impacts and controls of CSOs and SSOs. EPA 833-R-04001. Washington, DC

EPA (2020) U.S. environmental protection agency. EPA encourages Americans to only flush toilet paper https://www.epa.gov/ newsreleases/epa-encourages-americans-only-flush-toilet-paper . Accessed 15 Jul 2020

Eren B, Karadagli F (2012) Physical disintegration of toilet papers in wastewater systems: experimental analysis and mathematical modeling. Environ Sci Technol 46(5):2870-2876. https://doi. org/10.1021/es203589v

FDA (2017) U.S. Food \& Drug Administration. Food code - 2017 recommendations of the United States Public Health Service. https://www.fda.gov/media/110822/download. Accessed $15 \mathrm{Jul}$ 2020

GB standards, GB/T 20810-2018 (2018) Toilet tissue paper (including toilet tissue base paper)

Hebei Province (2020) Epidemic prevention and control in public toilets. https://zfcxjst.hebei.gov.cn/zhengcewenjian/tfwj/202002/ t20200218_285041.html. Accessed 15 Jul 2020

Heller L, Mota CR, Greco DB (2020) COVID-19 faecal-oral transmission: Are we asking the right questions? Sci Total Environ 729:138919. https://doi.org/10.1016/j.scitotenv.2020.138919
Heim S, Schwarzbauer J (2013) Pollution history revealed by sedimentary records: a review. Environ Chem Lett 11(3):255-270. https://doi.org/10.1007/s10311-013-0409-3

Huang D, Liu X, Jiang S et al (2018) Current state and future perspectives of sewer networks in urban China. Front Environ Sci Eng 12(3):2. https://doi.org/10.1007/s11783-018-1023-1

Jacques O (2020) Coronavirus toilet paper shortage creates havoc as flushed items block sewer pipes. https://www.abc.net.au/ news/2020-03-30/coronavirus-toilet-paper-shortage-leads-tosewer-blockages/12100036 Accessed 12 July 2020

Madhura L, Singh S, Kanchi S et al (2019) Nanotechnology-based water quality management for wastewater treatment. Environ Chem Lett 17(1):65-121. https://doi.org/10.1007/s1031 1-018-0778-8

MOUURD (2017) Ministry of Housing and Urban-Rural Development of the People's Republic of China. Design standards for public toilets in urban areas. https://www.mohurd.gov.cn/ wjfb/201703/t20170306_230861.html. Accessed 15 Jul 2020

MOUURD (2019) Ministry of Housing and Urban-Rural Development of the People's Republic of China. Advancing toilet revolution in China. https://www.mohurd.gov.cn/zxydt/20191 1/t20191120_242778.html. Accessed 15 Jul 2020

Park S, Lee C, Park D et al (2020) Detection of SARS-CoV-2 in fecal samples from patients with asymptomatic and mild COVID-19 in Korea. Clin Gastroenterol Hepatol. https://doi.org/10.1016/j. cgh.2020.06.005

Parker TJ (2020) Houston sewer overflow reports double during COVID-19 crisis. https://abc13.com/flushing-coronairus-sewer -houston-public-works/6052681/. Accessed 12 July 2020

PGBM (2020) People's Government of Beijing Municipality. Press conference on COVID-19 cases, prevention and control. https ://www.beijing.gov.cn/shipin/interviewlive/274.html. Accessed 11 July 2020

Regnery J, Friesen A, Geduhn A et al (2019) Rating the risks of anticoagulant rodenticides in the aquatic environment: a review. Environ Chem Lett 17(1):215-240. https://doi.org/10.1007/ s10311-018-0788-6

Shao S, Zhu Y, Peng Y et al (2020) Quality analysis of toilet paper in Shanghai 2019. China Pulp Pap Ind 41(09):40-42

Sharma VK, Jinadatha C, Lichtfouse E (2020) Environmental chemistry is most relevant to study coronavirus pandemics. Environ Chem Lett 18(4):993-996. https://doi.org/10.1007/s10311-02001017-6

TAPPI (2017) Technical association of the pulp and paper industry. Flushability standards. https://www.tappi.org/content/Events/ Tissue \%25202017/Conference\%2520Proceedings/3A.2_Lunde en.P.pdf. Accessed 15 Jul 2020

Tijani JO, Fatoba OO, Babajide OO, Petrik LF (2016) Pharmaceuticals, endocrine disruptors, personal care products, nanomaterials and perfluorinated pollutants: a review. Environ Chem Lett 14(1):27-49. https://doi.org/10.1007/s10311-015-0537-z

Tmall, JD, Suning.com (2020) Best sellers in toilet paper. https:// list.tmall.com/search_product.htm?spm=a220m.1000858.10007 24.4.339944ccHAhhhp\&q=\%D6\%BD\%BD\%ED\%BE\%ED\%D6 $\%$ BD\&sort $=$ d\&style. Accessed 15 Jul 2020

Usman M, Farooq M, Hanna K (2020) Existence of SARS-CoV-2 in wastewater: implications for its environmental transmission in developing communities. Environ Sci Technol 54(13):77587759. https://doi.org/10.1021/acs.est.0c02777

Walmart and Amazon.com (2020) Best sellers in toilet paper https ://www.walmart.com/browse/household141essentials/paper -plastic/1115193_1073264?cat_id=1115193_1073264_11493 84, https://www.amazon.com/gp/bestsellers/hpc/15342981/ ref=sr_bs_5_15342981_1 
WeExpats (2018) Throwing away your used toilet paper in Mexico. https://www.weexpats.com/throwing-away-used-toilet-paper -mexico-mexicans-dont-flush-tp. Accessed 15 Jul 2020

Williams J (2020) New Orleans sewers backing up as residents resort to toilet paper alternatives. https://www.nola.com/news/coronavirus/ article_29fca3dc-6acb-11ea-b33f-c7e67e00e4d8.html. Accessed $15 \mathrm{Jul} 2020$

Wu Y, Guo C, Tang L et al (2020) Prolonged presence of SARSCoV-2 viral RNA in faecal samples. Lancet Gastroenterol Hepatol 5(5):434-435. https://doi.org/10.1016/S2468-1253(20)30083-2

Yao J, Guo J, Cheng L et al (2018) Research on toilet paper used in public toilets. Technol Eco Guide 26(11):182-183
Zhejiang Province (2020) Strengthening the management of public health in public toilets. https://jst.zj.gov.cn/art/2020/2/6/art_15699 71_41883767.html. Accessed 15 Jul 2020

Publisher's Note Springer Nature remains neutral with regard to jurisdictional claims in published maps and institutional affiliations. 